\title{
Correction to: The Lagrange coefficients of Vinti theory
}

\author{
Ashley D. Biria ${ }^{1}$ \\ Published online: 25 June 2020 \\ (c) Springer Nature B.V. 2020
}

\section{Correction to: Celestial Mechanics and Dynamical Astronomy (2020) 132:26 https://doi.org/10.1007/s10569-020-09966-4}

In the first paragraph of Introduction, the last sentence should read as "Vinti (1966a, b) later generalized the potential to include $J_{3}$ effects (Der and Bonavito 1998), but the focus of this paper is on the symmetric potential".

The line under equation (108) should read as "Substituting Eq. (108) into Eq. (107) and simplifying the result leads to a compact expression for $\sin \Delta f / 2$ as".

In Conclusions, the first line should read as "The Lagrange coefficients of Vinti theory are developed in various forms for the first time, embedding a fundamental astrodynamics concept in a spheroidal geometry that naturally captures planetary oblateness in the dynamics". The original article has been corrected.

Publisher's Note Springer Nature remains neutral with regard to jurisdictional claims in published maps and institutional affiliations.

The original article can be found online at https://doi.org/10.1007/s10569-020-09966-4.

Ashley D. Biria

biria.ashley@gmail.com

1 Los Angeles, CA, USA 